\title{
Despite early fears, first Republican budget cuts bode well for science
}

Washington. The budget for basic scientific research has emerged virtually unscathed from the first round of Republican budget cuts in the US House of Representatives, strengthening hopes that the major science agencies will escape the zeal of the new majority in congress.

The House is in the process of passing two rounds of budget rescissions - sets of proposals to withhold money already allocated for the current financial year which ends on 30 September. These represent almost $\$ 20$ billion in savings. But while the cuts will affect plans to build research laboratories and industrial technology programmes, support for basic research is virtually untouched.

The cuts are the first step in the 104th Congress's promised assault on public spending. But they reveal a set of priorities producing some relief in the science community. "Given the magnitude of the cuts in other programmes, one can regard this as a good sign," says Al Teich, director of science policy at the American Association for the Advancement of Science (AAAS).

In a package that cut a total of $\$ 4.3$ billion, most of it from education and social programmes, the House appropriations subcommittee responsible for the Departments of Labor, Health and Human Services, and Education, chaired by John Edward Porter (Republican, Illinois), cut just $\$ 70$ million from this year's \$11-billion budget for the National Institutes of Health (NIH).
In addition, the NIH will lose $\$ 50$ million in construction funds, largely for a new administrative building it no longer wants, and \$20 million for an extramural programme designed to help renovate university laboratories.

Similarly, a package of cuts totalling $\$ 9.4$ billion from the subcommittee responsible for Veterans' Affairs, Housing and Urban Development and 'independent agencies', chaired by Jerry Lewis (Republican, California), axed only $\$ 66$ million from the budget of the National Aeronautics and Space Administration (NASA) - and nothing from that of the National Science Foundation (NSF).

The NASA cuts would save \$27 million by closing the Consortium for International Earth Science Information Network (CIESIN) at Saginaw, Michigan. In addition, $\$ 10$ million would be cut from the operation costs for the Hubble Space Telescope, $\$ 25$ million from the $\$ 1.3$-billion Mission to Planet Earth Programme, and \$1 million from the cost of flying the private jet used by Dan Goldin, NASA's administrator.

In a separate package already approved by the full House, NASA lost $\$ 400$ million for a new wind tunnel complex, and NSF lost $\$ 132$ million for facilities construction (see Nature, 373, 552; 1995). In both cases, the agencies involved had said they were not ready to spend the money appropriated by last year's Congress.

At the Department of Energy, members

\section{Spirits enter into an electronic medium}

London. Visitors to a 'showcase of information technology' in Brussels last week had the opportunity to view on a computer screen an historical image of Sir Arthur Conan Doyle (right), courtesy of the British Library. The 'psychic photo', from the early twentieth century Barlow Collection, is part of a sample of high-resolution digital images mounted on a prototype viewing system set up by the library.

The system was chosen as one of 150 exhibits, organized to coincide with a G-7 ministerial conference on the Information Society in Brussels on 24-26 February. The exhibition is designed to increase awareness of the developing information society and to show some of its potential benefits.

The British Library launched the system a year ago to speed access to images in the library's holdings of books, manuscripts and photographs.

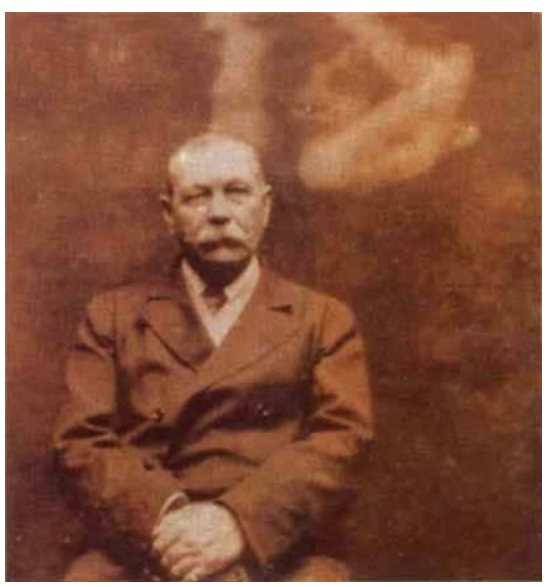

Users can search each collection using subject words, shelf marks or other indexes and once they have retrieved the images they want, they can view their selection as a high-resolution image on screen. of the appropriations subcommittee have proposed cuts of $\$ 35$ million in solar energy research, $\$ 50$ million in energy conservation programmes and $\$ 145$ million in environmental remediation. But research in nuclear fission and nuclear fusion, as well as basic research, was left untouched.

As expected, the research agency hit hardest by the cuts is the National Institute of Standards and Technology (NIST), whose technology programmes have been rapidly expanded by the Clinton administration. The package already passed by the house cut $\$ 107$ million this year from NIST's Advanced Technology Program, and an appropriations subcommittee proposed further cuts of \$20 million from NIST intramural research and $\$ 26$ million from the Manufacturing Extension Partnership, a programme to build manufacturing technology centres around the country.

Meanwhile, other appropriations subcommittees have cut $\$ 17$ million -10 per cent of the budget - from the National Biological Service, and a modest $\$ 650,000$ from Congress's own Office of Technology Assessment. So far the US Geological Survey, widely seen as a target of conservative Republicans, has not been cut at all.

Both NIST and the Department of Energy have issued statements denouncing the cuts, but the other science agencies have been maintaining an appropriate silence. But the cuts themselves may be vetoed by the Clinton administration.

The real power to impose its priorities will come when the House of Representatives sets the next budget, which covers the fiscal year beginning in October 1996. Observers say the cuts show a pattern familiar from the early Reagan years, when basic science was protected while education and technology programmes were cut.

Given the wave of cuts elsewhere, says Teich, the proposals are "perhaps an indication that Congress is going to go easy on research spending." He points out that this would be consistent with what Republican leaders such as Newt Gingrich (Republican, Georgia), the House Speaker, and Robert Walker (Republican, Pennsylvania), the chairman of its science committee, have been saying since November.

Colin Macilwain

\section{French blood affair}

Paris. The list of those charged with 'poisoning' in France's contaminated-blood affair rose to eight last week, with the indictment of Gérard Jacquin, the former director of bioindustry at the National Blood Transfusion Centre (CNTS).

D.B. 